\title{
Estrogen receptor $\alpha$ is involved in the regulation of ITGA8 methylation in estrogen receptor-positive breast cancer
}

\author{
Jingxun Wu ${ }^{1 \#}$, Jianghong Cheng ${ }^{2 \#}$, Fuxing Zhang ${ }^{3 \#}$, Xianyang Luo ${ }^{4,5,6}$, Zhiming Zhang ${ }^{1,6^{\wedge}}$, Shuai Chen ${ }^{1,2,4,5,7}$ \\ ${ }^{1}$ Department of Medical Oncology, The First Affiliated Hospital of Xiamen University, Xiamen, China; ${ }^{2}$ Shaanxi Key Laboratory of Brain Disorders \\ and School of Basic Medical Science, Xi'an Medical University, Xi'an, China; ${ }^{3}$ Department of General Surgery, The First Affiliated Hospital, Xiamen \\ University, Xiamen, China; ${ }^{4}$ Department of Otolaryngology-Head and Neck Surgery, The First Affiliated Hospital of Xiamen University, Xiamen, \\ China; ${ }^{5}$ Xiamen Key Laboratory of Otolaryngology Head and Neck Surgery, Xiamen, China; ${ }^{6}$ Teaching Hospital of Fujian Medical University, \\ Fuzhou, China; ${ }^{7}$ Institute of Basic and Translational Medicine, Xi'an Medical University, Xi'an, China. \\ Contributions: (I) Conception and design: S Chen, Z Zhang; (II) Administrative support: J Wu; (III) Provision of study materials or patients: J Cheng, \\ F Zhang; (IV) Collection and assembly of data: J Wu, J Cheng, X Luo; (V) Data analysis and interpretation: All authors; (VI) Manuscript writing: All \\ authors; (VII) Final approval of manuscript: All authors. \\ \#These authors contributed equally to this work. \\ Correspondence to: Shuai Chen. Department of Otolaryngology-Head and Neck Surgery, The First Affiliated Hospital of Xiamen University or \\ Institute of Basic and Translational Medicine, Xiamen, China. Email: chenshuai@xmu.edu.cn; Zhiming Zhang. Department of Medical Oncology, \\ The First Affiliated Hospital of Xiamen University, Xiamen, China. Email: zhangzhiming164@aliyun.com.
}

Background: Integrin subunit $\alpha 8$ (ITGA8) methylation has been associated with the development of several cancers, but its contribution to breast cancer remains unclear. The present study aimed to investigate the methylation status of ITGA8, and the underlying regulatory mechanisms of ITGA8 methylation in breast cancer.

Methods: ITGA8 expression was investigated using the Gene Expression Profiling Interactive Analysis 2 (GEPIA2) database and the Breast Cancer Gene-Expression Miner v.4.4 (bc-GenExMiner v4.4). The association between ITGA8 expression levels and the survival rate of breast cancer patients was evaluated using The Cancer Genome Atlas (TCGA) database and Gene Expression-based Outcome for Breast Cancer Online (GOBO): Gene Set Analysis. Methylation-specific PCR (MSP) was used to detect the methylation of ITGA8. Protein level of ITGA8 was determined by Western blot analysis.

Results: ITGA8 was expressed at low levels in human breast cancer cells compared to non-tumorigenic breast cells and breast tissue, and was upregulated in estrogen receptor (ER)-positive tissue compared with ER-negative tissue $(\mathrm{P}<0.01)$. ITGA8 gene expression was negatively associated with breast tumor stage and survival rate in all breast cancer patients. However, ER-positive patients with low ITGA8 expression showed poorer distant metastasis-free survival (DMFS) and recurrence-free survival (RFS) rates than patients with high ITGA8 expression. This was not observed in the ER-negative population. Mechanistically speaking, hypermethylation of ITGA8 was discovered in ER-positive breast cancer cells. Administration of the methylation inhibitor, 5-aza-2'-deoxycytidine (5-aza-dC), significantly elevated protein expression of ITGA8 in ER-positive breast cancer cells compared to ER-negative cells. The positive association between ITGA8 status and methylation was also observed in clinical tissue specimens. When treated with 17-beta-estradiol, an antagonist of ER $\alpha, 5$-aza-dC-induced upregulation of ITGA8 in ER-positive breast cancer cells was no longer observed.

Conclusions: Low ITGA 8 expression in ER-positive breast cancer might be caused by the hypermethylation of ITGA8, a process dependent on ER $\alpha$. Our findings provide an important foundation for investigations into ITGA8-targeted treatment strategies for ER-positive breast cancer.

^ ORCID: 0000-0002-1406-3710. 
Keywords: Integrin subunit $\alpha 8$ (ITGA8); Estrogen receptor $\alpha$; DNA methylation; Breast cancer

Submitted Jun 09, 2020. Accepted for publication Jul 27, 2020.

doi: $10.21037 /$ atm-20-5220

View this article at: http://dx.doi.org/10.21037/atm-20-5220

\section{Introduction}

Breast cancer is the second most common malignancy and the leading cause of cancer death in women worldwide (1). It is associated with the steroid hormone estrogen (2), with estrogen receptor (ER)-positive cancers accounting for $70 \%$ of all breast cancer cases. In patients over 70 years old, this proportion is as high as $85 \%$ (3). Although endocrine therapy is the preferred treatment method for hormone receptor-positive breast cancer, some patients can develop either primary or secondary drug resistance, prompting the need for novel therapeutic targets to overcome multidrug resistance (4).

Integrins, a family of transmembrane glycoproteins composed of an $\alpha$ and $\beta$ subunit can mediate cell-cell and cell-matrix interactions (5), and cell adhesion, migration, and differentiation (6). Importantly, a wide range of integrin abnormalities have been observed in cancer cells $(7,8)$. The prognosis of several types of cancers, including nonsmall-cell lung cancer (NSCLC), glioblastoma and gastric cancer, is closely correlated with integrin expression status (9-14). Integrin subunit $\alpha 8$ (ITGA8) belongs to the alpha integrin family of transmembrane cell surface receptors (15). Accumulating evidence indicates a close association between ITGA 8 and tumorigenesis. For example, low ITGA8 expression is associated with poor prognosis for overall survival (OS) in clear cell renal cell carcinoma patients (16). Highly expressed ITGA8 is able to induce epithelialmesenchymal transition (EMT) in early relapse multiple myeloma $(M M)$ patients, leading to enhanced migration and invasion abilities of MM cells (17). Furthermore, the expression of the ITGA8 gene is associated with colorectal carcinogenesis (18). However, the functional role of ITGA8 in breast cancer has not yet been characterized.

Several studies have demonstrated aberrant DNA methylation in breast cancer. Promoter methylation of tumor suppressor genes is generally tumor-specific, and is one of the most common epigenetic events in tumors $(19,20)$. Gene expression and methylation profiles can be used as clinical biomarkers to predict drug response and prognosis of breast cancer $(21,22)$. Integrin $\alpha 4$ methylation is frequently observed in primary breast cancer cells, and is associated with the histologic grade of tumors and lymph node metastasis (23). H3K4 trimethylation of integrin $\alpha v \beta 6$ and integrin $\alpha \mathrm{M}$ promoters have a promotive effect on the metastasis of ovarian cancer (24). Importantly, aberrant promoter methylation of ITGA8 has been observed more frequently in ovarian cancer cells compared to normal human ovarian surface epithelial cells, suggesting that ITGA8 may be a candidate tumor marker (25). However, whether aberrant methylation of ITGA8 is involved in the development and progression of breast cancer remains unclear.

Our findings demonstrated that ITGA8 showed low expression and was hypermethylated in ER-positive breast cancer patients. We next determined the association between ITGA 8 and tumor stage and survival rate of breast cancer and clarified if and how methylated ITGA8 was dependent on ER $\alpha$ in the breast cancer cells. Our data highlights the potential for aberrant methylation of ITGA8 to serve as a tumorigenic marker, and provides a basis for further investigations into ITGA8-targeted treatment strategies for ER-positive breast cancer.

We present the following article in accordance with the MDAR reporting checklist (available at http://dx.doi. org/10.21037/atm-20-5220).

\section{Methods}

\section{Subjects}

A total of 30 breast cancer tissue specimens and 15 paracancerous tissue specimens were obtained from the First Affiliated Hospital of Xiamen University. A signed informed consent form was obtained from all subjects, and this study was approved by the ethics committee of the First Affiliated Hospital of Xiamen University (no. KY2015-054). All procedures performed in this study involving human participants were in accordance with the Declaration of Helsinki (as revised in 2013). The clinicopathological characteristics of these patients are summarized in Table 1. 
Table 1 Correlation between ITGA8 expression and clinicopathological characteristics of ER-positive breast cancer patients

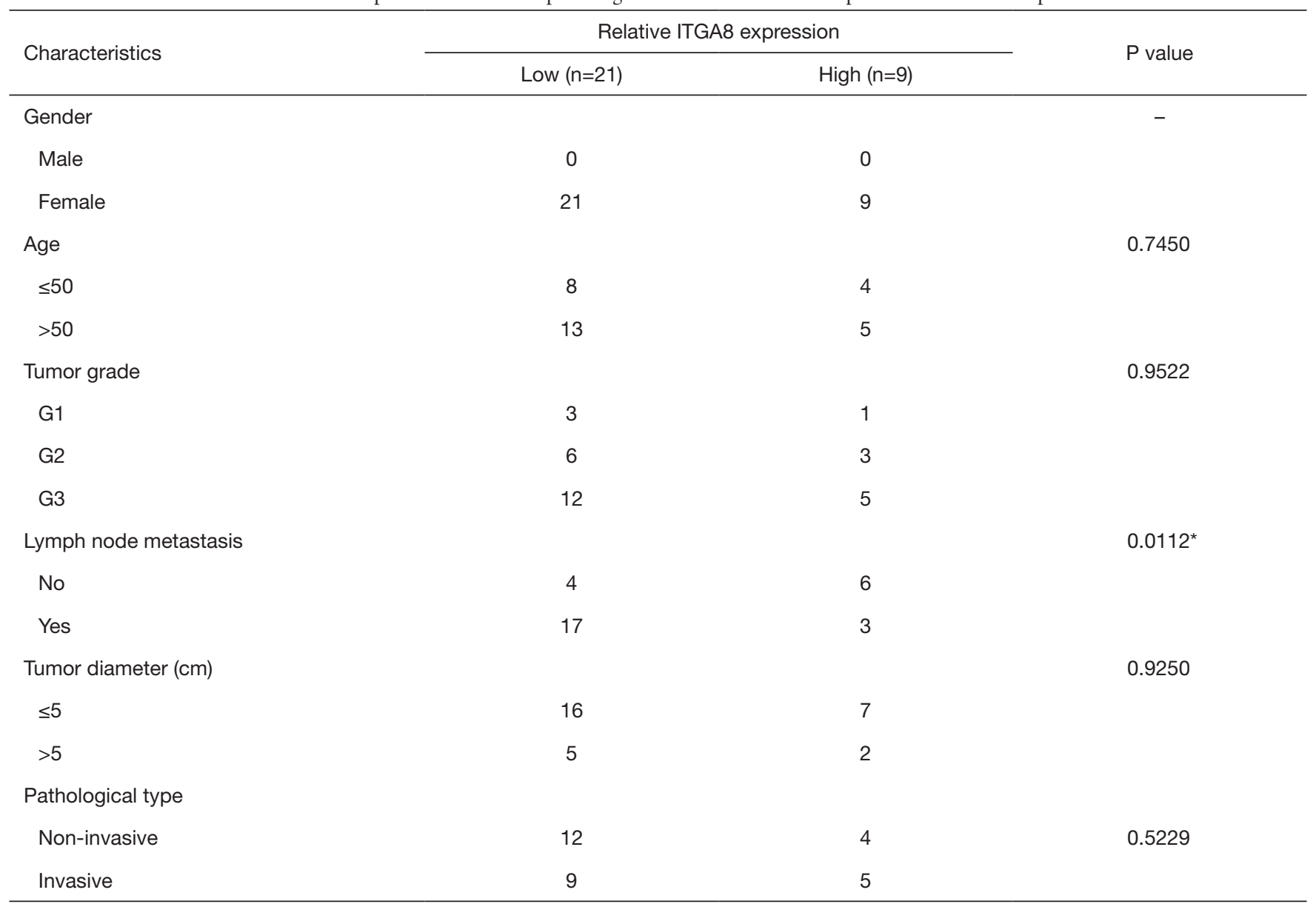

*, $\mathrm{P}<0.05$ was considered statistically significant.

\section{Immunobistochemistry}

After being heated in an oven for 30 minutes at $60^{\circ} \mathrm{C}$, slides were deparaffinized in xylene and rehydrated in graded ethanol. Antigens were retrieved by incubating the slides in $0.01 \mathrm{M}$ citrate salt solution ( $\mathrm{pH}$ 6.0), and then sections were blocked with $5 \%$ bovine serum albumin (BSA) for 1 hour at room temperature (RT). Sections were incubated with a primary antibody against ITGA8 (ab243027, Abcam, Cambridge, United Kingdom, 1:200) overnight at $4{ }^{\circ} \mathrm{C}$. The next day, endogenous peroxidase of tissue sections was neutralized by $3 \% \mathrm{H}_{2} \mathrm{O}_{2}$ for 15 minutes, and then slides were incubated with the secondary antibody (PV9001, ZSGB-BIO, China) for 15 minutes at RT. Staining results were visualized after sections were developed in 3,3'-diaminobenzidine (DAB) (ZLI-9017, ZSGB-BIO, China). Sections were viewed under a biological inverted microscope (IX51, Olympus, Japan). Comprehensive analysis of staining included measuring staining intensity and the number of positive cells (negative: -; weakly positive:,$+<30 \%$; middling positive:,$++ 30 \%-50 \%$; strongly positive:,$+++>50 \%)$. Five high-power fields for each sample were chosen for evaluation of relative ITGA8 levels by three independent pathologists using the Image Pro Plus software v6.0 (Media Cybernetics, Inc., Maryland, USA). Weakly positive $(<30 \%)$ cell staining was defined as low ITGA8 expression and middling-to-strong positive $(>30 \%)$ cell staining was defined as high ITGA8 expression.

\section{Cell culture and treatment}

ER-positive cell lines. MCF-7 and Zr-75-30, and ERnegative cell lines. MDA-MB-231 and BT-549. were purchased from the American Type Culture Collection (ATCC). Cells were cultured in Dulbecco's Modified Eagle 
Medium (DMEM) supplemented with 10\% fetal bovine serum (FBS, SH30070.03, HyClone, USA) and kept at $37{ }^{\circ} \mathrm{C}\left(5 \% \mathrm{CO}_{2}\right)$. One group of cells was exposed to the methylation-specific inhibitor, 5-Aza-2'-deoxycytidine (5-Aza-dC, $20 \mu \mathrm{M})$ alone, and were treated for 48 hours. For co-treatment with 5-Aza-dC and an antagonist of ERa, MCF-7 and Zr-75-30 cells were pre-treated with 17-betaestradiol (17-beta-E2, $\left.5 \times 10^{-9} \mathrm{~mol} / \mathrm{L}\right)$ for 24 hours. The $\mathrm{ER} \alpha$ blocker, ICI182,780 $\left(10^{-5} \mathrm{~mol} / \mathrm{L}\right)$ and $5-\mathrm{Aza}-\mathrm{dC}$, were added to cells in the experimental group for an additional 48 hours. Dimethyl sulfoxide (DMSO) was added to the control group of cells as a vehicle control.

\section{Methylation-specific polymerase chain reaction (MSP)}

Bisulfite conversion of DNA samples was performed using the EZ DNA Methylation ${ }^{\mathrm{TM}}$ Gold Kit (Zymo Research, USA) according to the manufacturer's instructions. PCR was performed on $1-4 \mu \mathrm{L}$ of the eluted DNA extracted from MCF-7, Zr-75-30, MDA-MB-231, and BT-549 cells, using the specific methylated or unmethylated sequences under the following conditions: $98^{\circ} \mathrm{C}$ for $10 \mathrm{~min}, 53^{\circ} \mathrm{C}$ for $30 \mathrm{~min}$, $53{ }^{\circ} \mathrm{C}$ for $6 \mathrm{~min}$, followed by 8 cycles at $37^{\circ} \mathrm{C}$ for $30 \mathrm{~min}$, then $4{ }^{\circ} \mathrm{C}$ storage. The primer sequences for methylationspecific PCR (MSP) are listed in Table S1. Amplified MSP products were separated on $2 \%$ agarose gels, and visualized after ethidium bromide staining.

\section{RNA extraction and quantitative real-time PCR (qRT-PCR)}

Total RNA was isolated from cells using TRIzol reagent (Roche, Indianapolis, IN, USA). Total RNA $(1 \mu \mathrm{L})$ was reverse transcribed to single-stranded cDNA using the ReverTra Ace ${ }^{\circledR}$ qPCR RT kit (Toyobo, Osaka, Japan). The reaction procedure was as follows: $65^{\circ} \mathrm{C}$ for $5 \mathrm{~min}, 37^{\circ} \mathrm{C}$ for $15 \mathrm{~min}$, and $98^{\circ} \mathrm{C}$ for $5 \mathrm{~min}$. Gene expression was quantified using the LightCycler 480 Real-Time PCR system (Roche Applied Science, Mannheim, Germany) using the following cycling conditions: $95^{\circ} \mathrm{C}$ for $10 \mathrm{~min}, 40$ cycles of $95^{\circ} \mathrm{C}(15$ sec), $60{ }^{\circ} \mathrm{C}(60 \mathrm{sec})$, and $1 \mathrm{cycle}$ of $50{ }^{\circ} \mathrm{C}(10 \mathrm{sec})$. Relative gene expression was normalized to GAPDH and calculated using the comparative Ct method. A list of primer sequences used in this study can be found in Table $S 2$.

\section{Western blot}

Total protein was extracted from cells using radioimmunoprecipitation assay (RIPA) buffer. After protein concentration was determined, equal amounts of protein samples $(30 \mu \mathrm{g})$ were separated by sodium dodecyl sulfate polyacrylamide gel electrophoresis (SDS-PAGE) and transferred onto an activated polyvinylidene fluoride (PVDF) membrane using electroblotting. After the membrane was blocked with $5 \%$ non-fat milk for 2 hours, the membrane was incubated with primary antibodies against ITGA8 $(1: 1,000)$ and $\beta$-actin $(1: 1,000)$ overnight at $4{ }^{\circ} \mathrm{C}$. After three washes with tris-buffered saline with Tween 20 (TBST), the membrane was then incubated with the secondary antibody at RT for 2 hours. Membranes were visualized using the ChemiDoc $^{\mathrm{TM}}$ MP Imaging System (BIO-RAD).

\section{Online database analysis}

The expression of ITGA8 in breast cancer tissue and normal tissue was analyzed using the Gene Expression Profiling Interactive Analysis 2 (GEPIA2) online analysis program. The differential expression of ITGA8 in different subtypes of breast cancer tissues, and the association between ITGA8 status and tumor stage (SBR standard classification), were determined using the Breast Cancer Gene-Expression Miner v4.4 (bc-GenExMiner v4.4). The correlation between ITGA8 status and survival rate was analyzed using The Cancer Genome Atlas (TCGA) database using R studio calculations and Gene Expression-based Outcome for Breast Cancer Online (GOBO): Gene Set Analysis.

\section{Statistical analysis}

All experiments were performed at least thrice. The differences between clinicopathological characteristics and ITGA8 expression were analyzed on GraphPad Prism 6.0 (San Diego, CA, USA) using Chi-square and Fisher's exact tests. Pearson's correlation coefficient was used to analyze the relationship between ESR1 and ITGA8 using SPSS 25.0 software (IBM, New York, NY, USA). Quantitative analysis of mRNA expression was conducted using a Student's $t$-test on GraphPad Prism. Data are presented as mean \pm standard error of mean (SEM). P values $<0.05$ were considered statistically significant.

\section{Results}

\section{ITGA8 was expressed at low levels in ER-positive breast cancer patients}

To investigate ITGA8 expression in breast cancer, ITGA8 
A

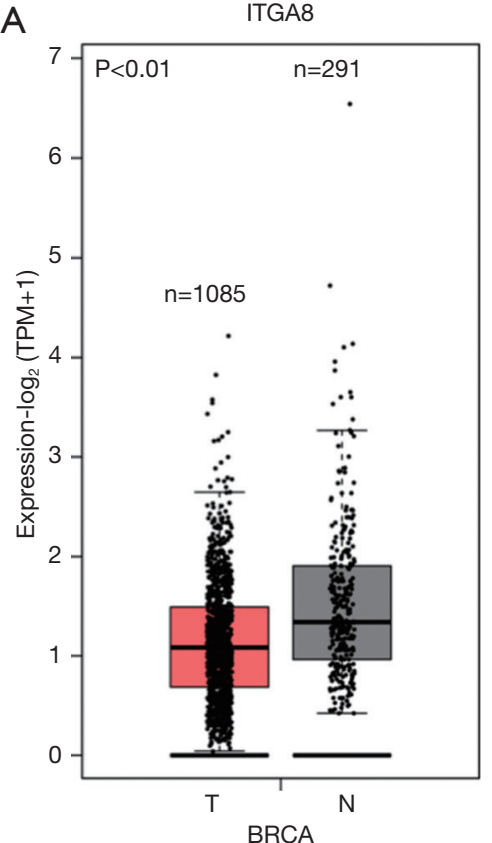

C

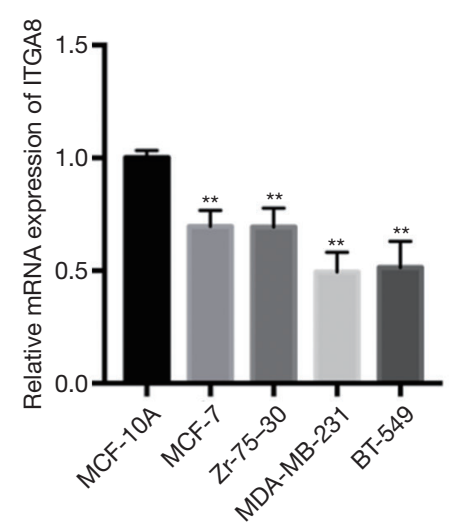

B

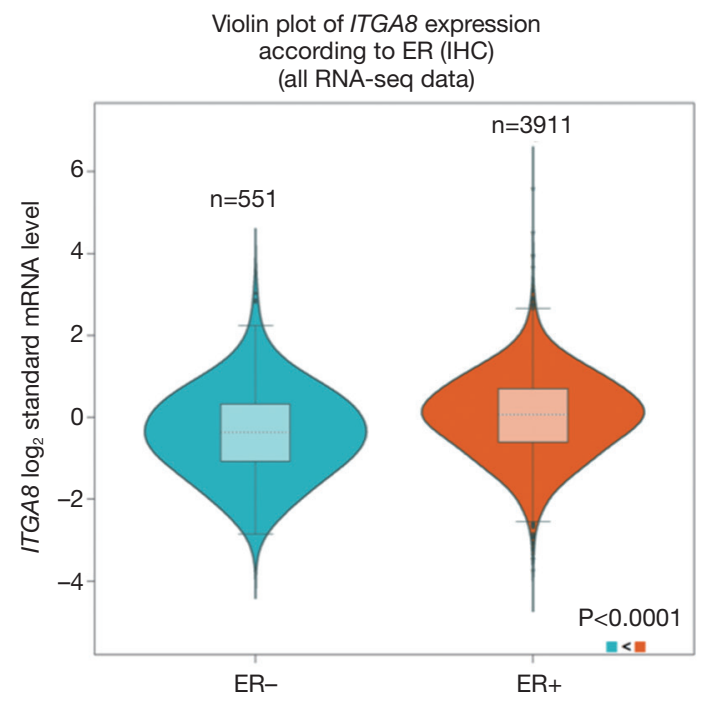

D

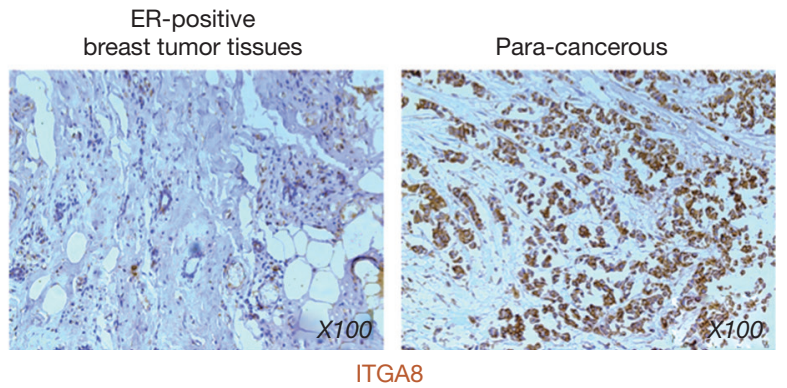

Figure 1 Integrin $\alpha 8$ (ITGA8) had low expression in primary breast cancer cells. (A) The expression of ITGA8 in breast cancer tumor tissue (red pillar, $\mathrm{n}=1,085$ ) and normal breast tissue (gray pillar, $\mathrm{n}=291$ ) was analyzed using the GEPIA2 database. (B) ITGA8 expression in ER-positive (orange square, $n=3,911$ ) and ER-negative (blue square, $n=551$ ) breast cancer patients was analyzed according to Breast Cancer Gene-Expression Miner v4.4 (bc-GenExMiner v4.4). (C) Expression levels of the ITGA8 gene in normal breast cells and four breast cancer cell lines were analyzed by quantitative RT-PCR. MCF-10A is a normal non-tumorigenic cell line. MCF-7 and Zr-75-30 cells are ERpositive breast cancer cell lines. MDA-MB-231 and BT-549 cells are ER-negative breast cancer cell lines. (D) IHC staining of tumor and paracancerous tissues of ER-positive breast cancer patients. ${ }^{* *}, \mathrm{P}<0.01$. IHC, immunohistochemistry; RT-PCR, real-time PCR; ER, estrogen receptor.

gene expression was analyzed in human breast cancer tissue and normal breast tissue using the GEPIA2 database. Results demonstrated a lower level of ITGA8 expression in breast cancer tissue $(\mathrm{n}=1,085)$ than in normal breast tissue $(\mathrm{n}=291)(\mathrm{P}<0.01)$ (Figure 1A). Furthermore, when using the bc-GenExMiner v4.4 database, we found that the expression of ITGAS in ER-positive breast cancer patients $(\mathrm{n}=3,911)$ was significantly higher than that in ER-negative breast cancer subjects $(\mathrm{n}=551)(\mathrm{P}<0.0001)$ (Figure 1B). ITGA8 expression levels were also higher in progesterone receptor $(\mathrm{PR})$-positive $(\mathrm{n}=3,498)$ and Her2-negative $(\mathrm{n}=3,582)$ breast cancer patients than in PR-negative $(n=828)$ and Her2-positive $(\mathrm{n}=661)$ breast cancer patients, respectively (Figure $S 1 A, B)$. Additionally, ITGA8 expression was 
significantly elevated in patients with non-triple negative breast cancer (non-TNBC) $(\mathrm{n}=4,119)$ compared to TNBC patients $(\mathrm{n}=317)(\mathrm{P}<0.0001)$ (Figure S1C). However, we did not observe a significant difference in ITGA8 status between breast cancer patients with lymph node metastasis and those without (Figure S1D). Notably, the expression of ITGA8 in breast cancer cells (MCF-7, Zr-75-30, MDAMB-231, and BT-549) was significantly lower than that of non-tumorigenic breast cells (MCF-10A). In comparison to ER-negative breast cancer cells, ITGA8 levels were increased in ER-positive breast cancer cells (Figure 1C). In addition, we investigated the expression of ITGA8 in fresh breast cancer tissues from 30 cases of ER-positive breast cancer patients. ITGA8 was expressed at low levels in tumor tissues compared to paracancerous tissues (Figure 1D). Among the 30 ER-positive breast cancer patients, 21 patients had low ITGA8 expression and 9 patients had high ITGA8 expression (Table 1). In summary, these data suggest that ITGA8 is expressed at low levels in breast cancer, and its expression is slightly higher in ER-positive compared with ER-negative breast cancer tissue.

\section{ITGA8 status was correlated with the survival rate of ER- positive breast cancer patients}

To evaluate whether ITGA8 could be used as a clinical diagnostic and prognostic marker for ER-positive breast cancer, we analyzed the correlation between the expression of ITGA8 and tumor characteristics. Combined with the results from the bc-GenExMiner v4.4 database, we discovered that there was a significant negative correlation between ITGA 8 status and tumor stage, where patients with a higher tumor grade had lower ITGA8 expression (Figure 2A). However, on the basis of the immunohistochemistry (IHC) staining results, we observed that ITGA8 status was not significantly correlated with patients' age, tumor grade, tumor diameter, or pathological type (Table 1). Of note, among the 20 breast cancer patients with lymph node metastasis, 17 of these patients showed low expression of ITGA8 ( $\mathrm{P}=0.0112)$ (Table 1). Additionally, we found that the overall survival (OS) rate in breast cancer patients with low ITGA8 expression $(\mathrm{n}=394)$ had a poorer prognosis than that in patients with high ITGA8 expression ( $\mathrm{n}=389)$ (Figure 2B). However, we did not find an association between ITGA8 status and OS in ER-positive or ER-negative breast cancer patients (Figure $S 2 A, B$ ). When we assessed the relationship between ITGA8 expression and distant metastasis-free survival (DMFS) or recurrence-free survival (RFS), results showed that ER-positive breast cancer patients with low ITGA8 expression had worse DMFS and RFS than patients with high ITGA8 expression (Figure 2C,D). By contrast, DMFS and RFS in ER-negative breast cancer patients had no correlation with ITGA8 expression status (Figure 2E,F). The above results suggest that because ITGA8 expression is significantly negatively correlated with lymph node metastasis in ER-positive patients and the OS rate in all breast cancer patients, ITGA8 can only be used as a prognostic indicator for DMFS and RFS in ER-positive breast cancer patients.

\section{ITGA8 was highly methylated in ER-positive breast cancer cells}

The MSP assay was employed to evaluate the methylation status of the ITGA8 promoter in four breast cancer cell lines, including ER-positive and ER-negative cells. Results showed that ITGA8 was highly methylated in ER-positive breast cancer cells (MCF-7 and zr-75-30) compared to ERnegative breast cancer cells (MDA-MB-231 and BT-549) (Figure $3 A$ ). Subsequently, we measured ITGA8 promoter methylation in 30 ER-positive breast cancer patients. We found that 19 out of the 30 cases showed ITGA8 promoter methylation $(63.3 \%)$, but only 4 out of the 15 cases of paracancerous cases had methylated ITGA8 (26.7\%) ( $\mathrm{P}=0.0287)$ (Figure 3B, Table 2). To further clarify the connection between DNA methylation and ITGA8 status, MCF-7 cells, zr-75-30 cells, MDA-MB-231 cells, and BT-549 cells were treated with 5-Aza-dC or DMSO to block the methylation events in these cells; then, ITGA8 protein expression was measured by western blotting. The expression of ITGA8 in ER-positive breast cancer cells (MCF-7 and zr-75-30 cells) significantly increased, while the expression remained unchanged in ER-negative breast cancer cells (MDA-MB-231 and BT-549 cells) after 5-Aza$\mathrm{dC}$ exposure (Figure 3C,D). These data suggest higher promoter methylation of ITGA8 in ER-positive breast cancer cells compared to ER-negative cells.

\section{ERa may be required for the regulation of ITGA8 promoter methylation in breast cancer}

To determine why hypermethylation of ITGA8 was only observed in ER-positive breast cancer cells, we analyzed the association between ER $\alpha$ gene expression (ESR1) and ITGA8 in 30 cases of ER-positive breast cancer tissue samples. As expected, there was a significant negative correlation 


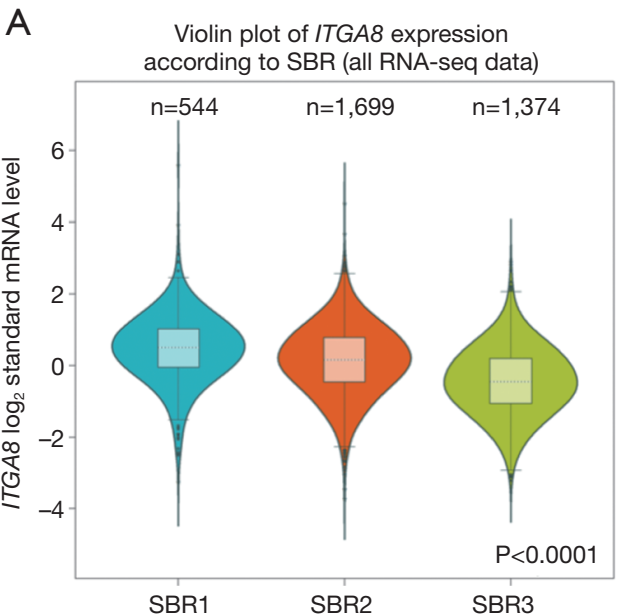

B - High ITGA8

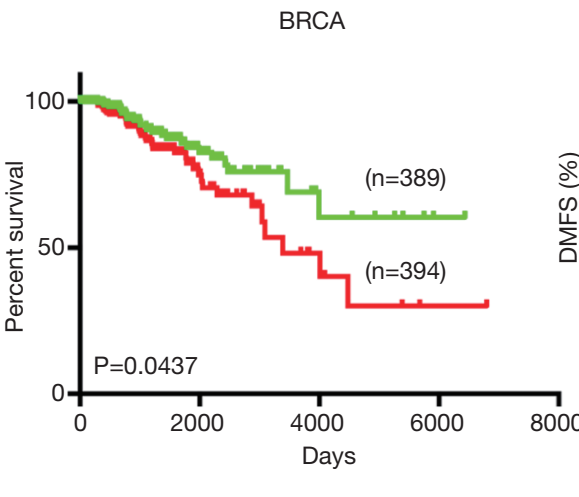

C

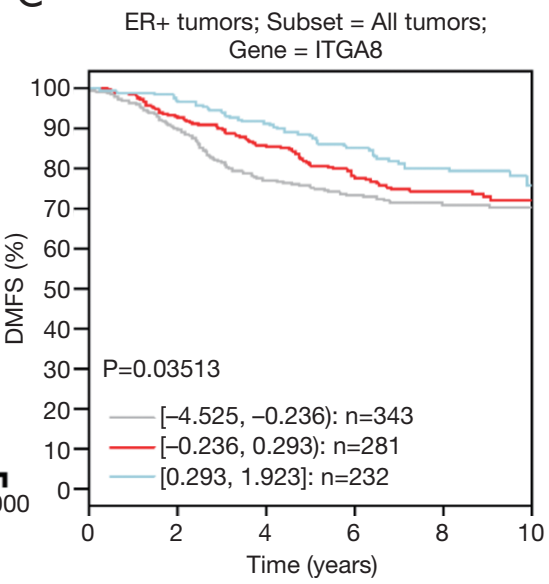

E

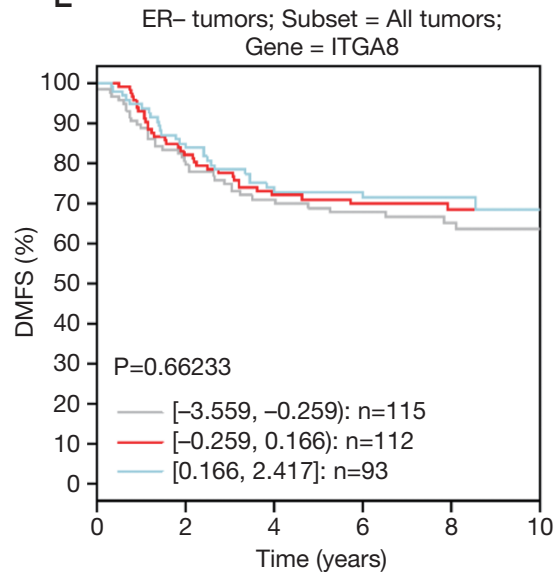

$\mathrm{F}$

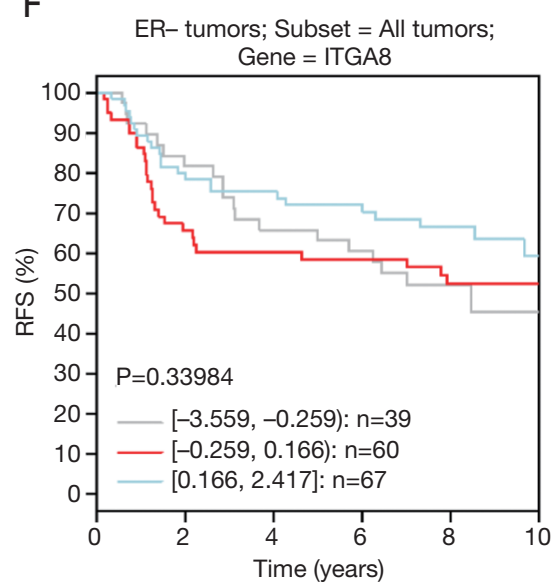

Figure 2 ITGA8 expression was correlated with survival rate in ER-positive breast cancer patients. (A) Association between ITGA8 expression status and SBR classification as determined by bc-GenExMiner v4.4 (544, 1,699, and 1,374 represent the number of patients, respectively). (B) The OS rate of patients with different ITGA8 expression status was analyzed using TCGA database and R studio analysis (low ITGA8: red lines, $\mathrm{n}=394$; high ITGA8: green lines, $\mathrm{n}=389$ ). The percentage of DMFS in ER-positive (C) and ER-negative (D) breast cancer patients with different ITGA8 expression status was analyzed using GOBO-Gene set analysis. The correlation between RFS in ERpositive (E) and ER-negative (F) breast cancer patients and ITGA8 expression status was calculated by GOBO-Gene set analysis (grey lines: low ITGA8 expression; red lines: medium ITGA8 expression; blue lines: high ITGA8 expression). ER, estrogen receptor; OS, overall survival; TCGA, The Cancer Genome Atlas; DMFS, distant metastasis-free survival; GOBO, Gene Expression-based Outcome for Breast Cancer Online; RFS, recurrence-free survival.

between ESR1 and ITGA8 expression (Figure 4A). We also discovered that ITGA8 expression was significantly higher in ER-positive breast cancer cells exposed to 5-Aza-dC, but this upregulation was reversed after exposure to ICI182,780, an ER $\alpha$ antagonist (Figure 4B,C). These data suggest that ER $\alpha$ may be involved in the process of ITGA 8 methylation or demethylation in ER-positive breast cancer cells.

\section{Discussion}

In the present study, we found that ITGA8 expression might be a prognostic marker for the DMFS and RFS of ERpositive breast cancer patients. We also demonstrated that the expression of ITGA8 was affected by its methylation status in ER-positive breast cancer cells. Additionally, ITGA8 promoter methylation and demethylation might be dependent on ER $\alpha$ in ER-positive breast cancer cells. 


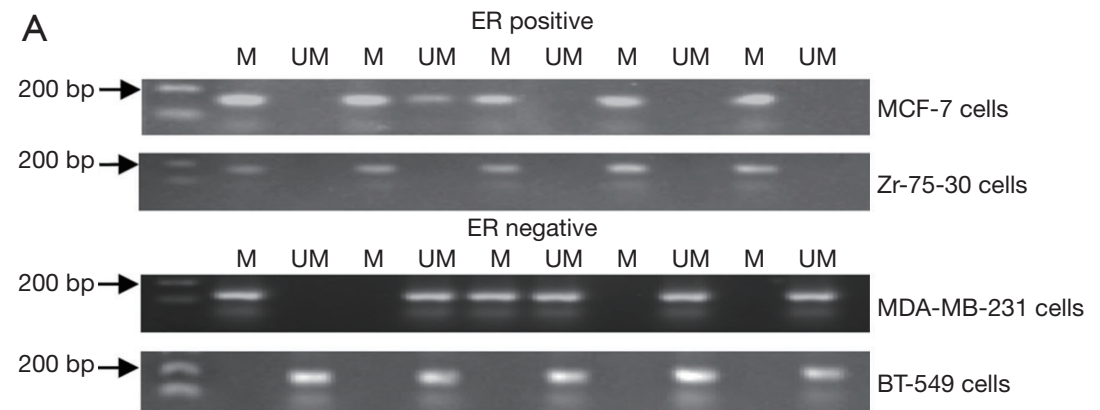

B
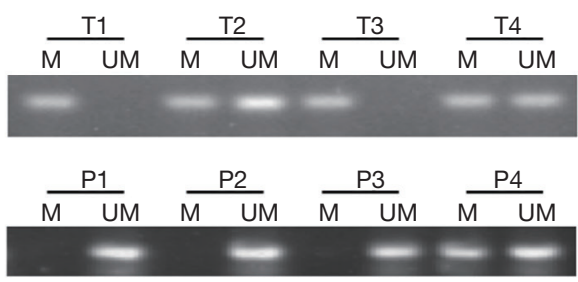

C

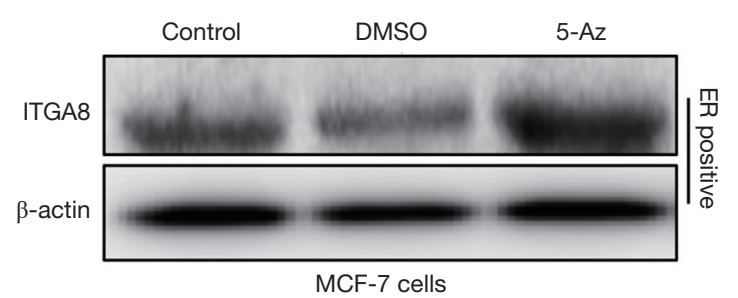

D
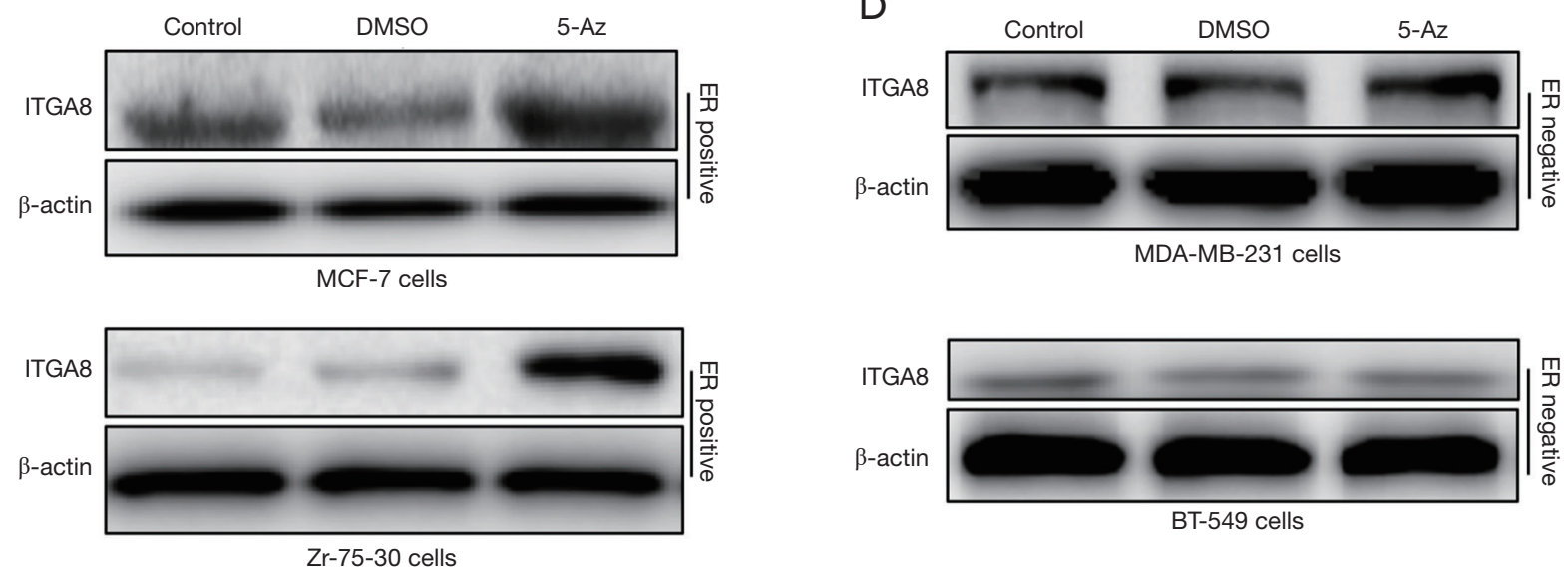

Figure 3 Hypermethylation of the ITGA8 promoter in ER-positive breast cancer cells. (A,B) The methylation status of the ITGA8 gene in breast cancer cells and ER-positive breast cancer tissues were measured by MSP assay. (C,D) ER-positive breast cancer cells (MCF-7 and zr75-30) and ER-negative breast cancer cells (MDA-MB-231 and BT-549) were treated with $20 \mu M$-Aza-CdR or DMSO for 48 hours. The effect of 5 -Aza-CdR on the protein expression of ITGA8 was evaluated by Western blotting analysis. $\beta$-actin protein was used as an internal reference. 5-Aza-CdR, 5-aza-2'-deoxycytidine; ER, estrogen receptor; MSP, methylation-specific PCR.

Table 2 ITGA8 methylation in breast cancer and paracancerous tissues (ER-positive)

\begin{tabular}{lcccc}
\hline & & \multicolumn{2}{c}{ Methylation } & \multirow{2}{*}{ Positive rate } \\
\cline { 3 - 4 } Histologic type & Numbers & - & + & $63.3 \%$ \\
Breast cancer & 30 & 11 & 19 & $0.0287^{\star}$ \\
Paracancerous & 15 & 11 & 4 & $26.7 \%$ \\
\hline
\end{tabular}

${ }^{*}, \mathrm{P}<0.05$ was considered statistically significant. ER, estrogen receptor.

Increasing evidence suggests that DNA methylation plays a pivotal role in the early diagnosis of breast cancer $(26,27)$, and that methylation of tumor suppressor genes contributes to the inhibition of tumorigenesis $(28,29)$. Our data suggest that ITGA8 may be a tumor suppressor gene in ER-positive breast cancer which may provide a basis for investigating therapeutic targeting of ITGA8 to treat ER-positive breast cancer.

ITGA8, part of a superfamily of cell adhesion receptors, has been shown to participate in the progression of multiple types of cancer (30). For example, ITGA8 expression was observed to be higher in adjacent normal tissue compared to colon adenocarcinoma (COAD) tissue (31), and has also been demonstrated to be a prognostic marker in clear cell renal cell carcinoma patients (32). In this study, although ITGA8 has lower expression in all breast cancer types compared to normal breast tissue, its expression varied in different breast cancer subtypes. For example, in contrast 
A

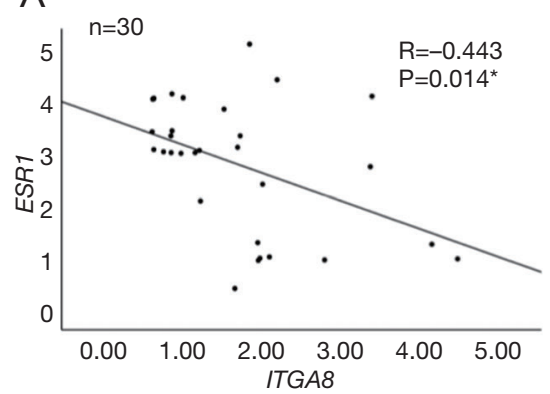

B

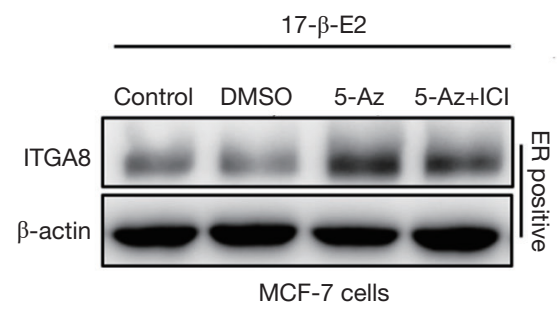

C

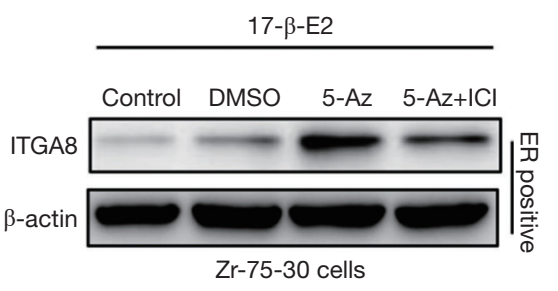

Figure 4 The role of ER in regulating ITGA8 methylation in breast cancer cells. (A) The correlation between ER $\alpha$ (encoded by ESR1 gene) and ITGA8 in 30 ER-positive breast cancer samples. ER-positive breast cancer cells MCF-7 (B) and Zr-75-30 (C) were pre-treated with 17 $\beta$ $\mathrm{E} 2$, and then incubated with 5-Aza-CdR and ICI182,780 for $48 \mathrm{~h}$. The protein level of ITGA8 was detected by Western blotting analysis. *, $\mathrm{P}<0.05$ was considered statistically significant. 17ß-E2, 17ß-Estradiol, sex hormone; ICI182,780, ER-alpha blocker; 5-Aza-CdR, 5-aza-2'deoxycytidine. ER, estrogen receptor.

to ER- and PR-negative breast cancer specimens, ITGA8 expression levels were higher in ER- and PR-positive patients. Additionally, in all breast cancer cases, there were no changes in ITGA8 expression in patients with or without lymph node metastasis; however, we found a negative correlation between nodal status in ER-positive breast cancer patients. Thus, ITGA8 might serve as a useful target for the diagnosis of nodal metastasis in ER-positive subjects. Because ITGA8 expression varies in different subtypes of breast cancer, further research is necessary to explore the molecular mechanisms underlying this differential expression.

Integrins have a well-recognized role in cancer cell migration, metastasis, and chemo-resistance $(33,34)$. Integrin $\alpha v \beta 6$ is upregulated in several cancer types and is correlated with survival rate, indicating its prognostic potential (35). In addition, high integrin $\alpha \mathrm{V} / \beta 3$ expression is associated with poor prognosis in acute myelocytic leukemia (AML) (36). Integrins have therefore been considered as valuable indicators for the early diagnosis and prognosis of several tumor types. Integrin $\beta 6$ (ITGB6) expression has prognostic value in invasive breast cancers, particularly in the HER2 ${ }^{+}$subtype (37). However, ERpositive and ER-negative breast cancers differ widely in clinical characteristics, treatment options, and prognostic markers (38). Ubiquitin-like modifier-activating enzyme 7 (UBA7) expression has been significantly associated with poor RFS and OS in ER-positive breast cancer patients, but not in ER-negative breast cancer patients (39). In this study, although a negative correlation between ITGA8 expression and tumor stage and OS was observed in all breast cancer cases, ITGA8 expression status did not affect the OS rates in each individual subtype including ER-positive and ERnegative subjects. Furthermore, we observed a significant negative correlation between ITGA8 and DMFS and RFS in ER-positive breast cancer patients, but not in ERnegative patients. These data suggest that ITGA8 may be a useful prognostic marker for DMFS and RFS in ERpositive patients specifically.

DNA methylation has been demonstrated to be significantly lower in ER-negative tumors than in ERpositive tumors $(40,41)$. For example, GSTP1 promoter hypermethylation is significantly more likely to be observed in ER-positive patients compared to ER-negative patients (42). In line with these previous findings, our present study demonstrated that ITGA8 promoter methylation in ERnegative breast cancer cells was lower than in ER-positive breast cancer cells. Furthermore, lower expression of ITGA8 in ER-positive breast cancer cells resulted from ITGA8 promoter hypermethylation. It has been well documented that aberrant methylation is closely related to ER. Genistein, a xenoestrogen found in large quantities in soybeans, has been demonstrated to induce DNA methylation in the tissues of reproductive organs (43-45). ER reduces the expression of excision repair cross complementing 1 (ERCC1), 8-oxoguanine glycosylase (OGG1) and mutL homolog 1 (MLH1) (DNA repair genes) potentially through regulating promoter hypermethylation (46). ER promotes CRHR2 expression via demethylation of its promoter in cardiomyocytes (47). In the present study, we observed that ITGA8 promoter methylation and demethylation may be dependent on ER $\alpha$. However, the mechanism by which ER regulates ITGA8 promoter methylation remains unclear. In previous studies, the ER- 
induced downregulation of the expression of cytosoliccatechol-o-methyltransferase (S-COMT) was related to the presence of two half palindromic estrogen response elements (EREs) and two putative CAAT enhancer binding protein $(\mathrm{C} / \mathrm{EBP})$ sites in the promoter for membranebound-COMT (48). ER suppressed COMT gene expression in association with alterations in CpG site-specific DNA methylation and the binding of DNA methylation-related proteins (5' cytosine methylation) and histone modifying enzymes ( $\mathrm{N}^{\prime}$ terminal deacetylation) (49). However, it remains unclear whether these transcription factors cooperate with enzymes to selectively silence ITGA8 expression, warranting further investigation.

\section{Conclusions}

In summary, we revealed low level ITGA8 expression in ER-positive breast cancer compared to ER-negative breast cancer and normal breast tissue. Furthermore, we found that low ITGA8 expression results from hypermethylation of the promoter region of the ITGA 8 gene, suggesting that ITGA8 may be a tumor-suppressor gene for ER-positive breast cancer. In terms of mechanism, the methylation of ITGA 8 might be regulated by ER $\alpha$. Thus, our results suggest that ITGA8 is a potential biomarker for ER-positive breast cancer and a potential target for the treatment of ER-positive breast cancer.

\section{Acknowledgments}

We are grateful for the support from The Youth Innovation Team of Shaanxi Universities and for the use of Gene Expression Profiling Interactive Analysis (GEPIA).

Funding: This work was supported by the Youth Scientific Research Project of Fujian Provincial Health and Family Planning Commission (no. 2016-2-63), the Research Foundation of Xi' an Medical University (no. 2017DOC18 and 2018GJFY04), the Natural Science Basic Research Plan in Shaanxi Province of China (no. 2018JQ8043), the Young Talent Fund of University Association for Science and Technology in Shaanxi (no. 20190309), and the Natural Science Foundation of China (no. 81802332).

\section{Footnote}

Reporting Checklist: The authors have completed the MDAR reporting checklist. Available at http://dx.doi.org/10.21037/ atm-20-5220
Data Sharing Statement: Available at http://dx.doi. org/10.21037/atm-20-5220

Conflicts of Interest: All authors have completed the ICMJE uniform disclosure form (available at http://dx.doi. org/10.21037/atm-20-5220). The authors have no conflicts of interest to declare.

Ethical Statement: The authors are accountable for all aspects of the work in ensuring that questions related to the accuracy or integrity of any part of the work are appropriately investigated and resolved. This study was approved by the ethics committee of the First Affiliated Hospital of Xiamen University (no. KY2015-054) and a signed informed consent form was obtained from all subjects. All procedures performed in this study involving human participants were in accordance with the Declaration of Helsinki (as revised in 2013).

Open Access Statement: This is an Open Access article distributed in accordance with the Creative Commons Attribution-NonCommercial-NoDerivs 4.0 International License (CC BY-NC-ND 4.0), which permits the noncommercial replication and distribution of the article with the strict proviso that no changes or edits are made and the original work is properly cited (including links to both the formal publication through the relevant DOI and the license). See: https://creativecommons.org/licenses/by-nc-nd/4.0/.

\section{References}

1. Hutchinson L. Breast cancer: challenges, controversies, breakthroughs. Nat Rev Clin Oncol 2010;7:669-70.

2. Reinert T, de Paula B, Shafaee $M N$, et al. Endocrine therapy for ER-positive/HER2-negative metastatic breast cancer. Chin Clin Oncol 2018;7:25.

3. Grann VR, Troxel AB, Zojwalla NJ, et al. Hormone receptor status and survival in a population-based cohort of patients with breast carcinoma. Cancer 2005;103:2241-51.

4. Lin M, Li Y, Qin S, et al. Ubiquitin-like modifieractivating enzyme 7 as a marker for the diagnosis and prognosis of breast cancer. Oncol Lett 2020;19:2773-84.

5. Hynes RO. Integrins: bidirectional, allosteric signaling machines. Cell 2002;110:673-87.

6. Hodivala-Dilke KM, Reynolds AR, Reynolds LE. Integrins in angiogenesis: multitalented molecules in a balancing act. Cell Tissue Res 2003;314:131-44.

7. Corfield AP, Berry M. Glycan variation and evolution in 
the eukaryotes. Trends Biochem Sci 2015;40:351-9.

8. Stawikowski MJ, Aukszi B, Stawikowska R, et al. Glycosylation modulates melanoma cell alpha2beta1 and alpha3beta1 integrin interactions with type IV collagen. J Biol Chem 2014;289:21591-604.

9. Elayadi AN, Samli KN, Prudkin L, et al. A peptide selected by biopanning identifies the integrin alphavbeta6 as a prognostic biomarker for nonsmall cell lung cancer. Cancer Res 2007;67:5889-95.

10. Goldberg I, Davidson B, Reich R, et al. Alphav integrin expression is a novel marker of poor prognosis in advanced-stage ovarian carcinoma. Clin Cancer Res 2001;7:4073-9.

11. Hazelbag S, Kenter GG, Gorter A, et al. Overexpression of the alpha $\mathrm{v}$ beta 6 integrin in cervical squamous cell carcinoma is a prognostic factor for decreased survival. J Pathol 2007;212:316-24.

12. Schittenhelm J, Schwab EI, Sperveslage J, et al. Longitudinal expression analysis of $\alpha \mathrm{v}$ integrins in human gliomas reveals upregulation of integrin $\alpha v \beta 3$ as a negative prognostic factor. J Neuropathol Exp Neurol 2013;72:194-210.

13. Vellon L, Menendez JA, Lupu R. $\alpha \mathrm{V} \beta 3$ integrin regulates heregulin (HRG)-induced cell proliferation and survival in breast cancer. Oncogene 2005;24:3759-73.

14. Zhang ZY, Xu KS, Wang JS, et al. Integrin alphanvbeta6 acts as a prognostic indicator in gastric carcinoma. Clin Oncol (R Coll Radiol) 2008;20:61-6.

15. Schnapp LM, Breuss JM, Ramos DM, et al. Sequence and tissue distribution of the human integrin alpha 8 subunit: a beta 1-associated alpha subunit expressed in smooth muscle cells. J Cell Sci 1995;108:537-44.

16. Lu X, Wan F, Zhang H, et al. ITGA2B and ITGA8 are predictive of prognosis in clear cell renal cell carcinoma patients. Tumour Biol 2016;37:253-62.

17. Ryu J, Koh Y, Park H, et al. Highly Expressed Integrinalpha8 Induces Epithelial to Mesenchymal Transition-Like Features in Multiple Myeloma with Early Relapse. Mol Cells 2016;39:898-908.

18. Kok-Sin T, Mokhtar NM, Ali Hassan NZ, et al. Identification of diagnostic markers in colorectal cancer via integrative epigenomics and genomics data. Oncol Rep 2015;34:22-32.

19. Shi J, Zhao C, Liu X, et al. The regulatory role of aberrant methylation of microRNA-34a promoter CpGs in osteosarcoma. Transl Cancer Res 2019;8:2328-38.

20. Wu NY, Zhang X, Chu T, et al. High methylation of ZNF582 in cervical adenocarcinoma affects radiosensitivity and prognosis. Ann Transl Med 2019;7:328.

21. Laird PW. The power and the promise of DNA methylation markers. Nat Rev Cancer 2003;3:253-66.

22. Miyamoto K, Ushijima T. Diagnostic and therapeutic applications of epigenetics. Jpn J Clin Oncol 2005;35:293-301.

23. Do SI, Ko E, Kang SY, et al. Aberrant DNA methylation of integrin alpha4 in human breast cancer. Tumour Biol 2014;35:7079-84.

24. Lyu T, Jiang Y, Jia N, et al. SMYD3 promotes implant metastasis of ovarian cancer via $\mathrm{H} 3 \mathrm{~K} 4$ trimethylation of integrin promoters. Int J Cancer 2020;146:1553-67.

25. Cai LY, Abe M, Izumi S, et al. Identification of PRTFDC1 silencing and aberrant promoter methylation of GPR150, ITGA8 and HOXD11 in ovarian cancers. Life Sci 2007;80:1458-65.

26. Liu H, Yan Z, Yin Q, et al. RUNX3 Epigenetic Inactivation Is Associated With Estrogen Receptor Positive Breast Cancer. J Histochem Cytochem 2018;66:709-21.

27. Scott CM, Wong EM, Joo JE, et al. Genome-wide DNA methylation assessment of 'BRCA1-like' early-onset breast cancer: Data from the Australian Breast Cancer Family Registry. Exp Mol Pathol 2018;105:404-10.

28. Billam M, Sobolewski MD, Davidson NE. Effects of a novel DNA methyltransferase inhibitor zebularine on human breast cancer cells. Breast Cancer Res Treat 2010;120:581-92.

29. Chen M, Shabashvili D, Nawab A, et al. DNA methyltransferase inhibitor, zebularine, delays tumor growth and induces apoptosis in a genetically engineered mouse model of breast cancer. Mol Cancer Ther 2012;11:370-82.

30. Takada Y, Ye X, Simon S. The integrins. Genome Biol 2007;8:215.

31. Gong YZ, Ruan GT, Liao XW, et al. Diagnostic and prognostic values of integrin alpha subfamily mRNA expression in colon adenocarcinoma. Oncol Rep 2019;42:923-36.

32. Lu XL, Wan FN, Zhang HL, et al. ITGA2B and ITGA8 are predictive of prognosis in clear cell renal cell carcinoma patients. Tumour Biol 2016;37:253-62.

33. Desgrosellier JS, Cheresh DA. Integrins in cancer: biological implications and therapeutic opportunities. Nat Rev Cancer 2010;10:9-22.

34. Longmate W, DiPersio CM. Beyond adhesion: emerging roles for integrins in control of the tumor microenvironment. F1000Res 2017;6:1612.

35. Niu J, Li Z. The roles of integrin alphavbeta6 in cancer. 
Cancer Lett 2017;403:128-37.

36. Johansen S, Brenner AK, Bartaula-Brevik S, et al. The Possible Importance of beta3 Integrins for Leukemogenesis and Chemoresistance in Acute Myeloid Leukemia. Int J Mol Sci 2018;19:251.

37. Desai K, Nair MG, Prabhu JS, et al. High expression of integrin beta6 in association with the Rho-Rac pathway identifies a poor prognostic subgroup within HER2 amplified breast cancers. Cancer Med 2016;5:2000-11.

38. Van't Veer L J DH, Van De Vijver M J. Gene expression profiling predicts clinical outcome of breast cancer. Nature 2002;415:530-6.

39. Lin M, Li Y, Qin S, et al. Ubiquitin-like modifieractivating enzyme 7 as a marker for the diagnosis and prognosis of breast cancer. Oncol Lett 2020;19:2773-84.

40. Suijkerbuijk KP, Fackler MJ, Sukumar S, et al. Methylation is less abundant in BRCA1-associated compared with sporadic breast cancer. Ann Oncol 2008;19:1870-4.

41. Ronneberg JA, Tost J, Solvang HK, et al. GSTP1 promoter haplotypes affect DNA methylation levels and promoter activity in breast carcinomas. Cancer Res 2008;68:5562-71.

42. Miyake T, Nakayama T, Naoi Y, et al. GSTP1 expression predicts poor pathological complete response to neoadjuvant chemotherapy in ER-negative breast cancer. Cancer Sci 2012;103:913-20.

43. Tang WY, Newbold R, Mardilovich K, et al. Persistent hypomethylation in the promoter of nucleosomal binding

Cite this article as: $\mathrm{Wu} \mathrm{J}$, Cheng J, Zhang F, Luo X, Zhang Z, Chen S. Estrogen receptor $\alpha$ is involved in the regulation of ITGA8 methylation in estrogen receptor-positive breast cancer. Ann Transl Med 2020;8(16):993. doi: 10.21037/atm-20-5220 protein 1 (Nsbp1) correlates with overexpression of Nsbp1 in mouse uteri neonatally exposed to diethylstilbestrol or genistein. Endocrinology 2008;149:5922-31.

44. Rietjens IM, Sotoca AM, Vervoort J, et al. Mechanisms underlying the dualistic mode of action of major soy isoflavones in relation to cell proliferation and cancer risks. Mol Nutr Food Res 2013;57:100-13.

45. Guerrero-Bosagna CM, Skinner MK. Environmental epigenetics and phytoestrogen/phytochemical exposures. J Steroid Biochem Mol Biol 2014;139:270-6.

46. Singh KP, Treas J, Tyagi T, et al. DNA demethylation by 5 -aza-2-deoxycytidine treatment abrogates 17 betaestradiol-induced cell growth and restores expression of DNA repair genes in human breast cancer cells. Cancer Lett 2012;316:62-9.

47. Cong B, Ni X. Estrogen up-regulates CRHR2 expression via demethylation of CRHR2 gene promoter in cardiomyocytes. Int J Cardiol 2014;172:496-7.

48. Xie T, Ho SL, Ramsden D. Characterization and implications of estrogenic down-regulation of human catechol-O-methyltransferase gene transcription. Mol Pharmacol 1999;56:31-8.

49. Wu Q, Odwin-Dacosta S, Cao S, et al. Estrogen down regulates COMT transcription via promoter DNA methylation in human breast cancer cells. Toxicol Appl Pharmacol 2019;367:12-22.

(English Language Editors: C. Betlazar and J. Reynolds) 
Table S1 Primer sequences for methylation-specific PCR

\begin{tabular}{|c|c|c|c|c|}
\hline Gene & Left M primer & Right M primer & Left U primer & Right U primer \\
\hline ITGA8-1 & TAGATTAGTCGCGAGGAGGC & CGTAATAACAATACCCGACG & TTAGATTAGTTGTGAGGAGGTG & ССАТАATAACAАТАСССААСАТСТ \\
\hline ITGA8-2 & TAGATTAGTCGCGAGGAGGC & CCGTAATAACAATACCCGACG & TTAGATTAGTTGTGAGGAGGTG & ССАТАAТАACAАТАСССААСАТСТ \\
\hline ITGA8-3 & TAGATTAGTCGCGAGGAGGC & CGTAATAACAATACCCGACG & TTAGATTAGTTGTGAGGAGGTG & CATAATAACAATACCCAACATCT \\
\hline ITGA8-4 & TAGATTAGTCGCGAGGAGGC & CCGTAATAACAATACCCGACG & TTAGATTAGTTGTGAGGAGGTG & CATAATAACAATACCCAACATCT \\
\hline ITGA8-5 & GAGTTITTGGTTTAGATTAGTCGC & GTATCCCGAATCGATACGCT & GTTITTGGTTTTAGATTAGTTGTGA & ТАCCСАТАТСССАААТСААТАСАСТ \\
\hline
\end{tabular}

Table S2 Primer sequences for RT-PCR

\begin{tabular}{lrr}
\hline Gene & Forward primer $\left(5^{\prime}-3^{\prime}\right)$ & Reverse primer $\left(5^{\prime}-3^{\prime}\right)$ \\
\hline GAPDH & AGGTGAAGTCGGAGTCA & GGTCATTGATGGCAACAA \\
ITGA8 & CTGTCAGGCGTTCAACC & CACCAAGACACTCGCTGTG \\
\hline
\end{tabular}
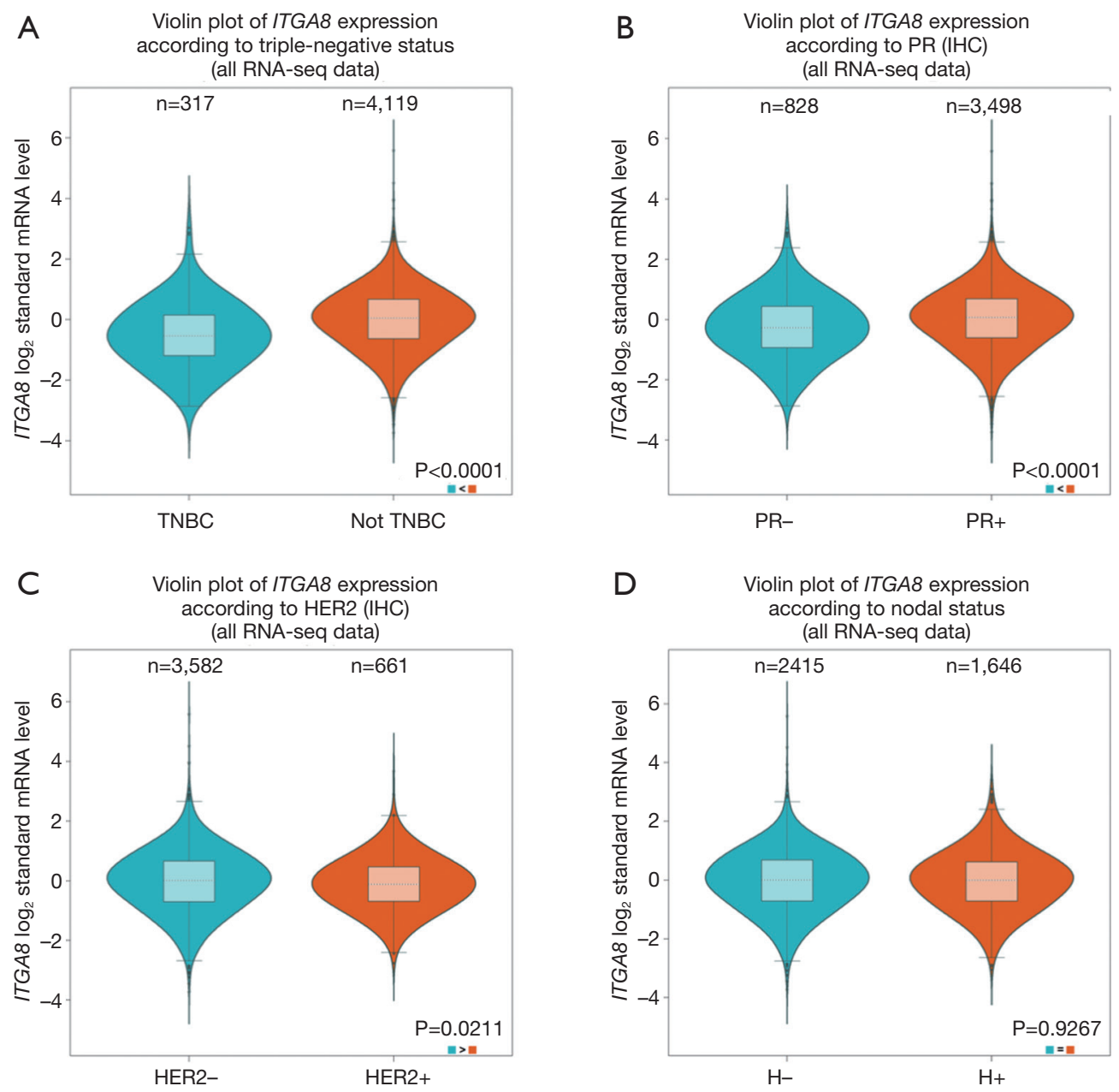

Figure S1 The expression level of ITGA8 was analyzed using the GEPIA2 database. (A) Differential expression of ITGA8 in patients with non-triple negative breast cancer (nonTNBC) and patients with TNBC as determined using bc-GenExMiner v4.4. ITGA8 expression in PR-positive and PR-negative breast cancer patients (B), and Her2-negative breast cancer patients and Her2-positive breast cancer patients (C) as analyzed using bc-GenExMiner v4.4. (D) Differential expression of ITGA8 in patients positive or negative for lymph node metastasis as determined by using bc-GenExMiner v4.4. IHC, immunohistochemistry; TNBC, triple negative breast cancer.
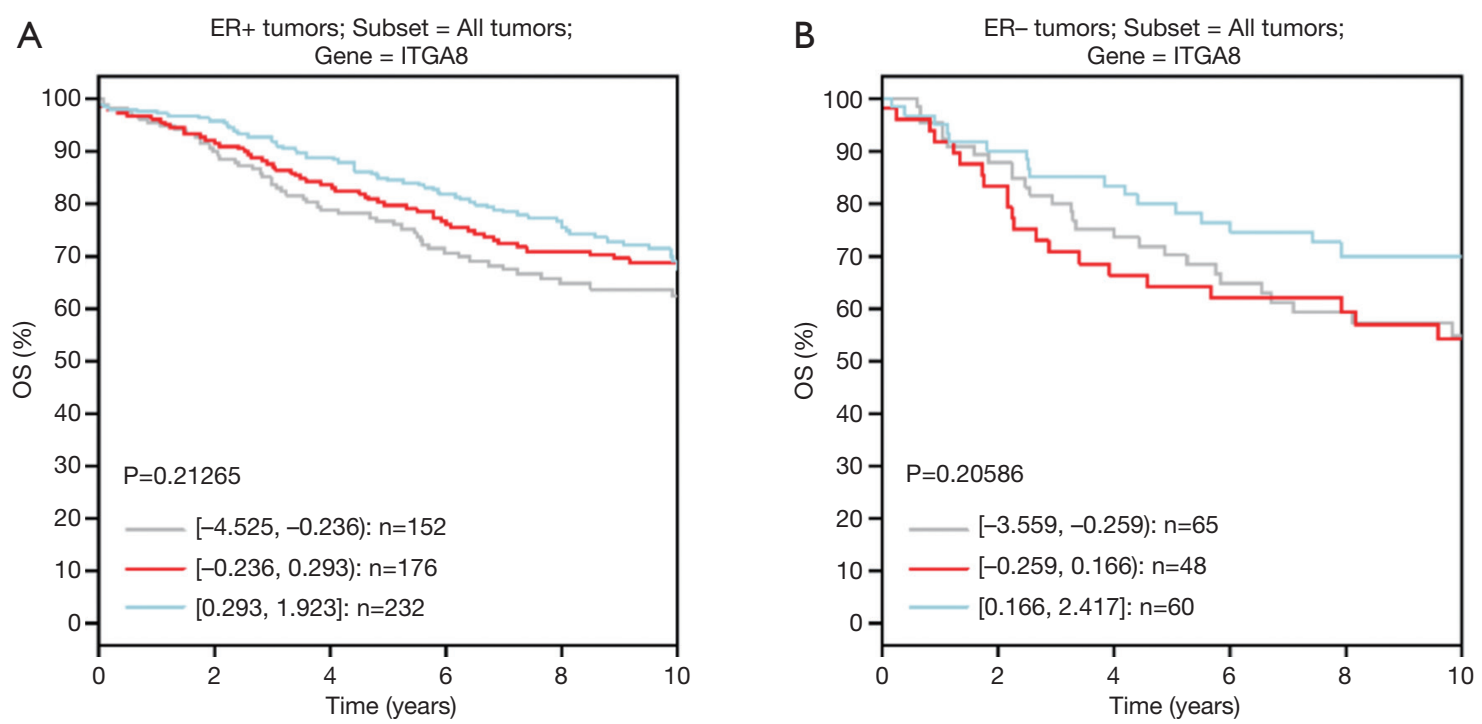

Figure S2 The expression of ITGA8 was analyzed by GOBO-Gene set analysis. (A,B) The OS rate of ER-positive and ER-negative breast cancer patients was analyzed using GOBO-Gene set analysis. Grey lines: low ITGA8 expression; red lines: medium ITGA8 expression; blue lines: high ITGA8 expression. ER, estrogen receptor; OS, overall survival; GOBO, Gene Expression-based Outcome for Breast Cancer Online. 